\title{
De peones a ejidatarios: la lucha por la tierra en la zona cafetalera del Soconusco, Escuintla, Chiapas
}

\section{From peones to ejidatarios: the struggle for land in the coffee zone Soconusco, Escuintla, Chiapas}

\section{Claudia Morales ${ }^{1}$}

\section{Resumen}

Se realiza una revisión del proceso de poblamiento y distribución de la tierra en la región fronteriza del sur de México, conocida como el Soconusco, Chiapas. En particular, en el municipio de Escuintla. Asimismo, se presenta un acercamiento al presente etnográfico desde la recreación de la historia local. Para realizar este vínculo se llevó a cabo una búsqueda hemerográfica en el Archivo General de la Nación, con relación a la lucha agraria y el proceso de dotación de tierra. Esta información se hiló con las historias orales de los interlocutores ahora ancianos que me compartieron sus recuerdos de esa época.

\footnotetext{
${ }^{1}$ Claudia Morales estudió Lengua y Literaturas Hispánicas en la UNAM y la maestría en Antropología Social, actualmente es becaría Fulbright-García Robles para estudios de doctorado en Estados Unidos. Email: claujmor@gmail.com
}

Revista Cadernos de Estudos Sociais e Políticos, v. 5, n. 9, jan-junho 2016 
A través de este diálogo, se pretendió recrear para el lector, lo más nítidamente posible, las percepciones, sensaciones y acontecimientos que tuvieron lugar en la zona de estudio. No sólo se procuró ofrecer información entorno a las disputas por la tierra, sino, también hacer sentir al lector los ambientes descritos. Ya que este contexto ayuda a explicar el mundo de los campesinos que fueron actores de este trascendental momento histórico.

Palabras clave: campesinos, café, repartición agraria, México, Soconusco.

\section{Abstract}

The article reviews the process of settlement and distribution of land in the border region of southern Mexico, known as the Soconusco, Chiapas. In particular, in the town of Escuintla. Also, an approach to ethnographic present is presented, from the recreation of local history. To make this link an hemerographic research was conducted at the General Archive of the Nation, (AGN) in relation to the agrarian struggle and the process of allocation of land. This information was spun with the oral histories of elderly peasants.

Through this dialogue, it was tried to recreate for the reader, as clearly as possible, perceptions, feelings and events that occurred in the study area. Not only it sought to provide information environment to land disputes, but also make the reader feel the environments described. Since this context helps explain the world of the peasants who were, and still are, actors in this crucial historical moment.

Keywords: peasants, coffee, land distribution, Mexico, Soconusco. 


\section{El Soconusco: un panorama de su población e identidades paralelas}

Durante un periodo de cinco meses (agosto-diciembre) viví en la Sierra de Chiapas en un ejido cafetalero llamado Hoja Blanca en el municipio de Escuintla, Chiapas, en la región del Soconusco, que se encuentra en la frontera entre Guatemala y México.

El camino desde los ejidos cafetaleros a los primeros asentamientos importantes de la región ofrece una panorámica de la vida cotidiana en esta importante región mexicana. Esta dinámica de desplazamiento es necesaria para los habitantes de la sierra, ya que existe dependencia de otros centros poblacionales más grandes como Huixtla o Tapachula. A continuación, presento un fragmento etnográfico que considero permite una primera aproximación a esta compleja zona fronteriza:

En particular, yo bajé a lo que llaman tierra caliente por primera vez a bordo del "Perrón de la Sierra", camión que sale de la localidad a las $3.00 \mathrm{am}$ en punto, de la hora de Dios, porque al igual que en los alrededores, en Hoja Blanca no se cambia "a la hora nueva" (el horario de verano).

El Perrón es un camión de redilas, pesado y viejo. En su parabrisas se lee "Marco Antonio" el nombre del hijo menor del dueño y conductor, a quien llamaremos Ignacio.

El Perrón recorre las calles de la colonia sin tocar el claxon. Pequeñas lámparas con timoratas luces caminan a encontrarlo. "Oiga don Ignacio, le encargo un mi casillero de huevo". Ignacio anota el pedido en una agobiada libreta con el nombre de la persona y el encargo. Por cada encargo se cobra un peso o dos de flete. 
Seguimos avanzando, lo único que ilumina la noche son los implacables faroles del Perrón de la Sierra. Ignacio toca el claxon en la comisaría y algunas personas salen de sus casas para subirse al autobús. Yo voy en la cabina (para ir en cabina, hay que hablar antes y apartar el asiento). De lo contrario, es preciso ir en las redilas. En la parte de atrás se han colocado bancas, y para poder subir hay que trepar sobre una escalera de metal diseñada para ese uso. Ahí suben ancianos, mujeres, niños.

Algunos pasajeros se trepan y seguimos nuestro comino, cruzando arroyos gélidos y delgados; la neblina que se extiende por la sierra empaña el parabrisas. Cada tanto, aunque cada vez menos frecuentemente, puede verse cruzar, tepezcuintes, armadillos $\mathrm{y}$ algún gato montés. También es común ver circular camiones con vidrios polarizados con un "banderillero" por delante. "Son los que trafican químico de Guatemala”, me explica Ignacio.

En esa ocasión, nos tocó la suerte de no encontrar a nadie, tampoco derrumbes, que en época de lluvia incomunican los ejidos de la sierra. Pero esta estación (invierno) no ha llovido de forma alarmante y por eso, sin ningún problema, alrededor de las cinco am llegamos a Belisario Domínguez, municipio de Motozintla. La gente comienza a bajarse, aún sigue sin amanecer, así que decido quedarme en el camión hasta que haya un poco de luz.

“¿Vas a cargar unos pollos?” Oigo que alguien le pregunta a Ignacio. $\mathrm{Y}$ en mi inocente o desconcertada percepción creo que se trata de animales. "Échalos, pues" contesta. Se detiene una combi de la que bajan mujeres, niños, hombres. Una mujer se sienta junto a mí, tiene los brazos gruesos y helados, tiembla. Las madrugadas son frías y por lo general cae una suave pero helada llovizna: son migrantes. 
Los migrantes miran a todas partes, silenciosos y agitados. Estamos por marcharnos cuando otro camión se pone en nuestro camino, nos tapa el paso. Un hombre se baja y saca con forcejeos a los "pollos" de El Perrón, sin que Ignacio pueda oponerse. Los migrantes se bajan de prisa. Su viaje apenas comienza, pero entrando a México saben que deben esconderse siempre, seguir órdenes. Al oír "vámonos", se levantan de prisa y se cambian de camión. El Perrón se queda vacío. Ignacio se baja. Discute con el otro conductor que le ha robado los pollos. Llegan al acuerdo de que le dará una parte del pasaje y los doscientos pesos que Ignacio pagó para que el de la combi llevara a los pollos. Ignacio regresa irreconocible, su rostro apacible se transforma, iba a ganar ahí mil pesos, descontando la gasolina, setecientos. Arroja al piso su linterna. Debido a eso, me bajo antes del camión en Belisario y espero a que comiencen a circular las combis que llevan a Huixtla. A las seis de la mañana me subo a la primera que encuentro. De Belisario a Huixtla el camino está pavimentado en cada una de sus muchas curvas. Las combis se detienen para recoger gente en el camino, y como vamos a Huixtla el transporte va especialmente lleno de estudiantes, enfermeras, profesores.

Finalmente, nos detenemos en el mercado, que es un alboroto constante de comerciantes. Su agitación sólo se vio mermada después del huracán $\operatorname{Stan}^{2}$, que dejó la zona incomunicada por casi un mes. Desde entonces, la recuperación ha sido lenta, ya que a la devastación del huracán se añade la quiebra general de los cafeticultores de la sierra que año a año deambulaban por el pueblo entre las tiendas, los restaurantes y las cantinas.

\footnotetext{
${ }^{2}$ Según Reyes Hernández (2006), el huracán Stan tocó tierra el 4 de octubre de 2005 de categoría I en Punta Roca Partida en Veracruz. Las lluvias afectaron además los estados de Oaxaca, Tabasco, y Chiapas, donde se desbordaron treinta y tres ríos. Siendo Chiapas y Veracruz las entidades más afectadas.
} 
Al brío del mercado, se suma que la ciudad es húmeda y calurosa. Por lo general, hay entre 30 y 45 grados, que se incrementan durante la quema de caña en el ingenio ${ }^{3}$. Anualmente durante la zafra, sobre las sábanas blancas colgadas en los patios, sobre las cabezas de los niños, sobre las calles recién barridas por las señoras: llueve una delgada hojuela de ceniza que al tocarla se deshace en los dedos. Yo he llegado en temporada de zafra y el calor incrementa.

Al recorrer Huixlta se pueden ver casas, tiendas y almacenes de café, de una olvidada opulencia. Ahora, hay nuevos comercios: sobre las vías del tren se han puesto puestos de pupusas, tacos raquíticos y ropa americana de "paca".

Los almacenes de café son enormes estructuras vacías y cubiertas por maleza, como barcos náufragos.

Camino hasta el río, que ahora corre tranquilo sobre un pavimento de rocas, como un niño que oculta sus travesuras: apenas en el 2005 inundó e incomunicó la zona, causando muchas muertes. Afectando en particular los márgenes del río, donde se asentaban anteriormente las cantinas y prostíbulos, que han vuelto a aparecer con el mismo auge de siempre. "hay gran cantidad de bares para el número de habitantes. Hay casi doce casas de billar siempre con clientes”, enunciaba el reporte hecho allá en 1939, pocas cosas han cambiado. Sin embargo, cada vez es más común ver a mujeres muy jóvenes, casi todas centroamericanas, sentadas en la puerta para atraer clientes. Me detengo en una tienda para comprar agua y platicar. En la calle la gente circula cubriéndose con mantas o sombrillas del calor, o montados en triciclos que funcionan como un

\footnotetext{
${ }^{3}$ Dependiendo de la temporada de lluvias, la zafra se lleva acabo de noviembre a abril.
}

Revista Cadernos de Estudos Sociais e Políticos, v. 5, n. 9, jan-junho 2016 
enjambre de taxis. Una señora se acerca a mí e intenta venderme el número de un "cachito de Melate", las tandas y las loterías son populares, sobre todo entre las mujeres centroamericanas que viven en Huixtla.

Decido hacer el recorrido a la ciudad de Tapachula, que sería la ruta que hace un cafeticultor al vender café y surtirse de mercancías. Para legar a Tapachula hay que tomar otra combi. Volvemos a bajar en un mercado, en esta ocasión en el mercado central del Tapachula, cerca del parque. En este lugar se conjuntan: turistas extranjeros distraídos y desubicados, niños guatemaltecos que venden dulces, migrantes africanos que causan sensación y dejan que les tomen fotografías, y comerciantes de Guatemala que venden toda clase de tiliches (cortaúñas, juguetes de plástico, cartas, peines).La ciudad, en comparación con Hoja Blanca, me parece tan cercana y lejana a la vez. Después de un tiempo viviendo en la localidad, Tapachula me parece abrumadora y confusa. Pienso en que el resto de pasajeros que bajaron conmigo desde la sierra, también deben estar a punto de regresar, porque a las dos en punto (a las tres sin contar el horario de verano) debemos estar junto al camión, esperando para regresar a Hoja Blanca.

Me apresuro a volver a Belisario, pero tengo que esperar, muchos de los pasajeros fueron a hacer trámites y ahora vienen de regreso, algunos vienen cargados de mercancía y agotados. Hay que hacer algo de tiempo, hasta que se llene el camión lo más que se pueda. Ignacio sube los encargos y anota en la libreta lo que ya ha comprado: jabón, huevos, clavos, gasolina, refrescos, un reloj de pulso con batería grande.

Antes de tomar camino, pasamos por un criadero de marranos. Los puercos chillan en su corral. Ignacio los observa con detenimiento, 
a él le encomendaron elegir el marrano adecuado. Señala a un marrano café con lunares negros. Entre varios pasajeros logran subirlo a la redila. Y después de forcejear, consiguen al fin amarrarlo. Se colocan en la redila los que pueden tolerar el olor. Los demás suben a la góndola, se sientan a la intemperie. Comenzamos a subir, el camión se zangolotea hacia los lados. Y el puerco gime, inconforme. A lo largo del camino suben jornaleros que trabajan en las fincas.

Volvemos a cruzar los mismos arroyos. La misma sierra laboriosa y majestuosa se extiende a nuestro alrededor. Algunas piedras gigantes, como huevos prehistóricos, rodean el camino. Suspiro. Todos estamos agotados y dormitamos. El puerco se revuelca en la parte de atrás. Lo compraron para el pago de Oportunidades, me explica Ignacio. Costó mil setecientos pesos, pero lo van a vender "ahora que paguen el apoyo", cuando algunos aprovecharán para comer carne. Hemos traído al elegido.

Finalmente, llegamos a la comandancia ejidal. La mayor parte de la gente se baja, los que pidieron encargos esperan. Una llovizna leve y gélida nos acompaña hasta la casa. Mañana se repetirá la misma rutina.

Me permito hacer esta digresión porque considero que el panorama regional actual, que pretendí bosquejar desde mis impresiones subjetivas (un espacio atravesado por la violencia, el empobrecimiento general y la falta de accesos y vialidades) está íntimamente ligado a un proceso histórico de dotación y lucha por la tierra en el estado de Chiapas. En particular, en la región del Soconusco, que por sus particularidades (que resumiré a continuación) es un espacio de alta movilidad de población. Ya que, históricamente, es un lugar de tránsito y destino, que configuró un espacio de interacciones complejas y 
dinámicas (no hay que olvidar además la zona tiene una estrecha relación con Guatemala y el resto de Centroamérica). Debido a la contigüidad geográfica de la región con Guatemala, y como se observa en el fragmento etnográfico, se ha constituido en una ruta alterna para el ingreso de migrantes centroamericanos y de otras nacionalidades en su travesía hacia el norte. La escasa vigilancia de agentes migratorios y de otras instancias gubernamentales propicia que los "polleros" o "coyotes" usen estos caminos para traficar humanos, pero también es aprovechado por el narcotráfico. No sólo es una zona fronteriza de tránsito de migrantes sino de lugar de destino laboral de miles de trabajadores (hombres, mujeres, niños) que llegan a la región a trabajar temporal o permanentemente

Por lo tanto, este espacio está fuertemente vinculado entre sí y cualquier alteración significativa, en cualquiera de sus puntos, tendrá posiblemente repercusiones en el conjunto.

Los siguientes mapas nos dan una idea de la ubicación geográfica del municipio de Escuintla, perteneciente a la región del Soconusco, Chiapas, México, que se localiza en los límites de la Sierra Madre y de la Llanura Costera del Pacífico, predominando el terreno montañoso, sus coordenadas geográficas son $15^{\circ} 19^{\prime} 92^{\prime} \mathrm{N}$. 


\section{Mapa 1. Región X. Soconusco, Chiapas, México}

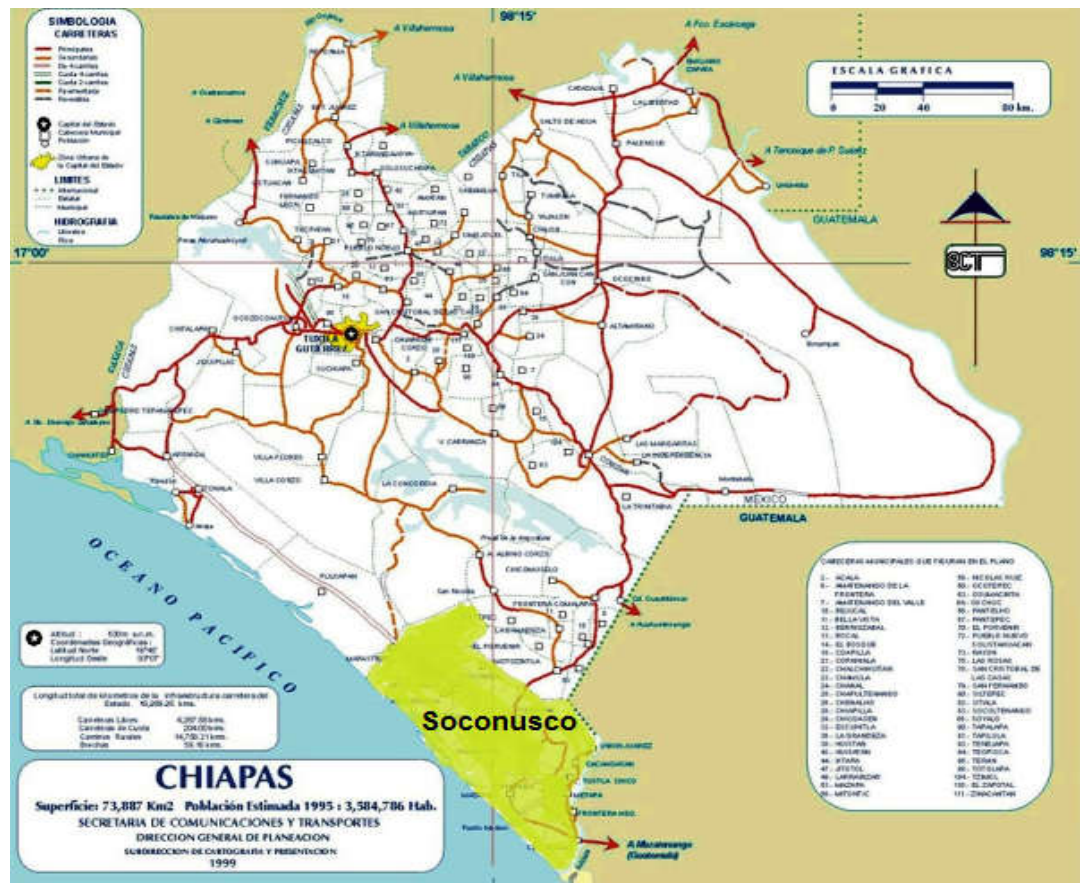

Fuente: Elaboración propia, modificación al mapa original "Mapa Chiapas 1999" SCT

Revista Cadernos de Estudos Sociais e Políticos, v. 5, n. 9, jan-junho 2016 


\section{Mapa 2. Municipio Escuintla, Chiapas, México}

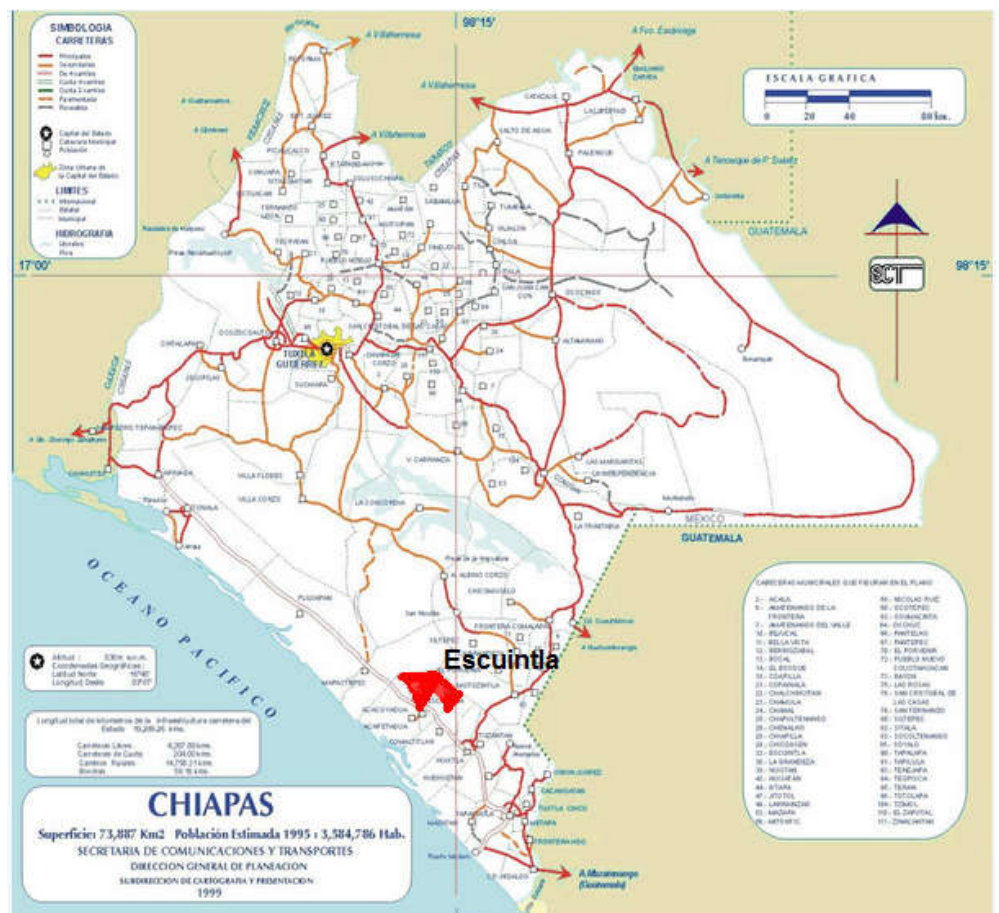

Fuente: Elaboración propia, modificación al mapa original "Mapa Chiapas 1999" SCT

Escuintla, el municipio señalado, es uno de los asentamientos humanos más antiguos del estado de Chiapas, ya que fue fundado como pueblo en 1486, y para 1700 se convirtió en la capital de la provincia del Soconusco hasta 1792 (Pérez de los Reyes, 2012).

El Soconusco, actualmente, es un territorio que coincide en tierra casi puntualmente con la región geográfica del mismo nombre. La cual “comprende una sección de la costa del Pacífico en el sur de México que se extiende desde las cercanías de la actual población de Pijijiapan, Chiapas,

Revista Cadernos de Estudos Sociais e Políticos, v. 5, n. 9, jan-junho 2016 
hasta unos cuantos kilómetros al este de la frontera mexicano-guatemalteca (Voorthies, 1991, citado por Alcalá Moya, 1999:115).

Históricamente esta región ha sido un punto de referencia e importancia económica para el estado de Chiapas. Posterior a la conquista, muy pronto ganó fama como una tierra fértil, célebre por el cultivo de cacao. Incluso del otro lado del Atlántico, recreándose en crónicas y testimonios como un destino ideal para aventureros en busca de fortuna. También el desafortunado Miguel de Cervantes (1547-1616), buen conocedor de la popularidad del Soconusco, pidió en una carta al rey la encomienda del Soconusco como pago a sus años de miliciano. Aunque la petición del escritor nunca fue tomada en cuenta, nos da cuenta de la temprana importancia de la región como un lugar fértil para los cultivos debido a su diversidad de nichos. "En el rectángulo no mayor de 50 kilómetros de ancho por 150 kilómetros de largo, donde se ubica el Soconusco terrestre, se identifican varios pisos ecológicos: la costa tropical, la sábana húmeda, las selvas medias y altas que alcanzan en el volcán Tacaná más de 4000 metros de altura sobre el nivel del mar (Alcalá Moya, 1999:127).

Como consecuencia de la variación de alturas, al llegar al Soconusco, lo primero que se notará será el contraste entre estos "pisos" o niveles que menciona Alcalá Moya (1999). Dependiendo desde dónde se observe, el paisaje variará. Por ejemplo, si se observa desde las montañas, a más de 1200 metros de altura, en el corredor del café (o la "sierra", como le llaman los habitantes), se podrán observar las inescrutables serranías que se desdoblan una tras otra, hasta convertirse en valles extensos y verdes que chocan contra la línea pulcra del mar. Quizá por este paisaje, muchas localidades tienen nombres como "Mira mar", "Horizonte", o "Vista Hermosa". En cambio, si se observa desde la costa, se podrán ver primero las pasturas verdes y 
uniformes, deslizándose junto a la carretera. Al fondo las montañas, que se elevan sobre el horizonte cubiertas por nubes espesas que se dejan caer sobre ellas.

Para la década de los noventa, del siglo pasado, Graciela Alcalá Moya (1999) hace la siguiente esquematización de los niveles o pisos, mencionados, en relación con los tipos de poblamiento asentado en igual número de franjas en distintas alturas:

1. En la llanura costera hasta los 200 metros sobre el nivel del mar - la población se concentra en Tapachula, Puerto Madero y Huixtla, principalmente, aunque la población dispersa por caseríos perdidos entre esteros y pampas de agua, en municipios como Acacoyagua, Acapatahua, Mazatán, Villa Comaltitlán o Suchiate es de alrededor del 20\% del total de la población del municipio.

2. Más arriba, hasta los 500 metros sobre el nivel del mar aproximadamente, la población se instala en ciudades pequeñas de más de 5000 habitantes y en rancherías.

3. En la franca cafetalera la población dispersa es escasa, compuesta por algunos ejidatarios que todavía viven al lado de la tierra que trabajan, o se encuentra sujeta a las fincas.

4. Más arriba de los 1200 metros sobre el nivel del mar, la escasa población dispersa la conforman algunos ejidatarios que viven en su milpa con sus familias y los hombres que llegan a trabajar para ellos durante cortas temporadas al año.

Esta esquematización coincide, en gran medida, con la hecha por los habitantes de Hoja Blanca. Pero, con algunos matices, denominando "sierra" a la región en la que viven, entre los 800 y 1200 metros sobre el nivel del mar (ésta es una zona, predominantemente cafetalera, en la cual se encuentran las Revista Cadernos de Estudos Sociais e Políticos, v. 5, n. 9, jan-junho 2016 
fincas y ejidos visitados); de igual manera, tomando como ubicación la sierra, hacia arriba, a más de 1200 metros se encuentra lo denominado "tierra fría", lugar donde viven (según los habitantes de Hoja Blanca) "los indios", es decir, la zona habitada mayoritariamente por la etnia mam, que se dedica principalmente al cultivo de papa (esto es, el Porvenir, Bejucal de Ocampo, Siltepec, Motozintla) ${ }^{4}$. Asimismo, siguiendo esa misma lógica, hacia abajo, se ubica "tierra caliente", "allá abajo", "la costa"; la cual está constituida por las zonas bajas, en las cuales se encuentran las cabeceras municipales y administrativas que son Tapachula, Huixtla, Villa Comaltitlán, Tuzantán, Escuintla.

"Esta separación de cada espacio social y económico que tiene su asiento en cada franja de altura distinta en el Soconusco, está expresando una diferenciación social enorme, dentro de la cual el único espacio de identidad regional común es Tapachula, la ciudad en torno a la cual giran las actividades económicas de la región” (Alcalá Moya, 1999:129). Coincido con la aseveración de Graciela Alcalá Moya, agregando que cada zona asume una identidad en específico, la cual ha sido construida históricamente con relación a la lógica regional, y aunque en constante cambio, mantiene aún hoy algunas referencias estereotípicas, que responden a disputas e interacciones locales. Por ejemplo, hablando de forma general, se tiene la creencia, por parte de la gente "serrana" que "los de tierra fría" son gente

\footnotetext{
${ }^{4}$ El mam es un grupo maya que habita en el sureste de México y en Guatemala. [...] En México la población habita en los estados de Campeche, Quintana Roo y Chiapas: en este último se localizan en el sureste en la zona fronteriza con Guatemala, principalmente en la región de la Sierra Madre de Chiapas, en los municipios de Amatenango de la Frontera, Bejucal de Ocampo, Bella Vista, La Grandeza, Mazapa de Madero, Motozintla, El Porvenir y Siltepec. En la región Soconusco en los municipios de Acacoyagua, Cacahoatán, Frontera Hidalgo, Tuxtla Chico, Tuzantán, Unión Juárez, Huehuetán, Tapachula y Escuintla (CDI, 2009).
} 
muy trabajadora e "indita"; mientras que la gente de la costa es "abusiva y poco trabajadora". Mientras que para la gente de la costa, la "gente serrana" y la de "tierra fría" son, igualmente, "incivilizados", "tímidos" y "poco educados". Retrato lo anterior haciendo la salvedad de que estas definiciones no son unilaterales ni carentes de matices.

Además, la gente del lugar está en constante tránsito e interacciona de formas distintas, cambiando de estatus o posición; moviéndose continuamente de un espacio a otro y dialogando y resinificando su identidad. No ahondaré más con relación a este tema, sin embargo, me interesa describir algunos elementos de esta interacción, ya que se construye en espacios cotidianos. Sobre todo, para los habitantes de "tierra fría" y de "la sierra" es indispensable la relación con las poblaciones de la costa, por ser estas ciudades centros más grandes y poblados, ya sea para trabajar, educarse, asistir a centros de salud o simplemente para surtirse de mercancías.

Ahora bien, la localidad Hoja Blanca se localiza a 1200 metros de altitud, y es de propiedad comunal. Si bien, la localidad está adscrita a Escuintla, los vínculos con este municipio son casi estrictamente administrativos, ya que en un principio no había caminos para acceder al lugar; debido a esto, por generaciones, los vínculos de compra y venta del café se dieron primero con Villa Comaltitlán, Huixtla y Tapachula. Desde siempre, el acceso a las localidades de la sierra ha sido complicado, y la falta de carreteras que permitiera la fácil transportación del café y la adquisición de insumos diarios obligó a los habitantes de las escarpadas montañas a crear rutas propias.

Yo vine acá en el año 1957, en ese tiempo, las condiciones eran diferentes, estaba incomunicado Hoja Blanca. Antes que empezaran a correr los carros a Hoja Blanca, la gente de antes viajaba de [la finca] La Fortuna para Manacal, a Esperanza, luego 
a Providencia, y luego a Villa y ahí agarraban el tren para Huixtla o Tapachula. Ya de la estación para el centro y para regresar, igual. Su mercancía la dejaban ahí, pues, encargado en un lugarcito en la [finca] La Fortuna de ahí con mula hasta acá. En aquel tiempo estaba favorable su economía, la gente traía dos carros con mercancía: arroz, carbón y petróleo, en ese tiempo se usaba la panela (don Emilio, 78 años, Hoja Blanca entrevista por Claudia Morales Ramírez).

Por tanto, como se explicó, aunque la localidad está administrativamente adscrita a Escuintla en la región del Soconusco, para los habitantes Hoja Blanca forma parte de la sierra; y junto con otros ejidos, fincas y pequeñas propiedades integran una geografía local: un tejido de pequeñas propiedades conectadas por algunos tramos pavimentados, pero, sobre todo, por estrechas veredas en las montañas que permiten llegar de propiedad a propiedad caminando, atravesando los municipios de Huixtla, Escuintla, Villa Comaltitlán y Motozintla. Veredas que los trabajadores guatemaltecos y pobladores recorren diariamente, a veces caminando por horas: cargando un machete, botas de hule y una radio de baterías que sintoniza estaciones de Guatemala.

Los vínculos con estas regiones se han forjado, históricamente, siguiendo la lógica del comercio del café. Así, debido a que los mejores precios se consiguen secando el café y vendiéndolo en oro, los ejidatarios realizan el beneficio seco en la propiedad y, posteriormente, trasportan el grano para comerciarlo en alguna ciudad o pueblo cercano ${ }^{5}$.

\footnotetext{
5 El beneficiado húmedo es un proceso para transformar los frutos del cafeto de su estado uva a café pergamino. Este se desarrolla en dos fases: la primera es la húmeda o despulpe y la segunda es el secado que termina con la obtención de café pergamino seco para su almacenamiento (Procafé, 2012).
}

Revista Cadernos de Estudos Sociais e Políticos, v. 5, n. 9, jan-junho 2016 
Explicar esta dinámica es relevante, ya que articula una serie de interacciones locales que sólo pueden ser entendidas si son vistas a detalle y configuran el panorama que fue escenario de un proceso importante para la historia de México y Chiapas: la repartición agraria.

\section{Historia y conflicto en los cafetales de Chiapas}

Lo que generalmente se entiende como "el corredor del café" alude a las zonas altas del Soconusco, en las cuales se cultiva principalmente café. Y que se encuentra a una altura de entre 800 y 1200 metros de altura. Está constituida principalmente por fincas, ejidos y pequeñas propiedades, aunque la mayor parte de las pequeñas propiedades se convirtieron en ejidos como parte de un "plan de contingencia" ante la reestructura de las carteras vencidas, que los pusieron en peligro de perder sus propiedades. Estos nichos productivos están profundamente diferenciados entre grandes productores (finqueros) con más de dos mil hectáreas y los pequeños productores y ejidatarios que cuentan con entre veinte y tres hectáreas, respectivamente.

Sin embargo, como se ha mencionado, en la actualidad, ambos sistemas de cultivo han sido fuertemente afectados por los procesos multicanales que progresivamente han desmantelado el campo cafetalero. Las fincas, con mayor capital y poder adquisitivo, han diversificado sus actividades (turismo, cultivo de flores, piñón y aguacate), mientras que en los ejidos los ejidatarios han tenido menos capacidad de afrontar con éxito dichos cambios y han optado por otras estrategias de subsistencia como la migración interregional o internacional. 
Ahora bien, a través de la información hemerográfica que he recopilado así como la bibliográfica, aunado a un trabajo de campo de seis meses, me atrevo a decir que hay tres procesos paralelos para la población de la zona cafetalera del Soconusco: primero, la llegada de extranjeros que compraron tierras a finales del siglo XIX y principios del siglo XX; segundo, el asentamientos de sus trabajadores en tierras nacionales $y$, tercero, la paralela creación de ejidos.

Reseñaré brevemente cada uno de estos procesos, ya que la configuración histórica de los ejidos y el proceso conflictivo de dotación de tierra influyó en la situación actual de la región y en la forma de vida de los ejidatarios que lucharon por la tierra y hoy continúan vivos. Esta etapa de disputa por la tierra (1940-1970) coincide con la juventud de los interlocutores del estudio nacidos entre (1926-1936) y considero que este periodo forjó el imaginario que hoy existe de ellos, como personas fuertes y aguerridas, pues como se revisará a continuación, la relación conflictiva con los finqueros así como el proceso de poblar y producir una zona deshabitada requirió muchos esfuerzos por parte de estos campesinos.

Debo comenzar aclarando que ese proceso no fue abrupto ni poco conflictivo. Principalmente, porque gran parte de la acumulación de la tierra pertenecía legalmente a compañías o familias extranjeras. Según se consigna en los informes de la época, en la cual se fundaron los primeros ejidos (1939) el total de tierra en manos de extranjeros era de 434566.30 hectáreas.

Por ejemplo, algunos propietarios como Walter Kahle poseían 21608 937; seguido de su hijo Guillermo Kahale, con 20659792 hectáreas. Sin embargo, es en realidad imposible saber cuál era la verdadera extensión de 
tierra que pertenecía a estas fincas cafetaleras, como así informa el reporte citado:

Estos datos son tomados del registro de la propiedad, adolece de grandes defectos, pues las cantidades de extensión de tierra que se citan, no pueden comparar con las grandes extensiones de tierra con que cuentan los terratenientes extranjeros particularmente en la zona cafetalera del Soconusco donde se han hecho la mayor concentración de la propiedad de la tierra. Como decimos estos datos adolecen de grandes defectos, muchos nombres de fincas que aparecen en este documento en la práctica no existen y consideramos que la verdad sobre la propiedad de la tierra cafetalera en Chiapas sólo se aclarara en el momento de la aplicación de la reforma agraria. Tapachula, a 18 de septiembre de 1939. Firma Fernando G Cortés (Archivo General de la Nación).

Ahora bien, en un principio, los principales cultivos del Soconusco se daban en las tierras bajas y eran, sobre todo, maíz y cacao, producidos por rancheros locales que también practicaban la ganadería. Por su parte, en las zonas altas "tierra fría" los habitantes mam, en su mayoría, cultivaban la papa y el maíz en las zonas despoblados, en las que actualmente se encuentran los ejidos a los que me refiero; sin embargo, para finales del siglo XIX, con la llegada de los inversionistas extranjeros (de origen japonés, alemán, francés y estadounidense) comienza la producción cafetalera en el lugar, convirtiéndose desde entonces en su principal actividad económica. Lo anterior, ocurrió como parte de una política que favorecía la venta de propiedad e inversión extranjera, amparados por la "Ley de deslinde y colonización de terrenos Baldíos" publicada y reformada en 1883; “un año más tarde el gobierno de Díaz firmó un convenio con la compañia mexicana 
de colonización de San Francisco y le concedió 200 mil hectáreas en Chiapas para deslindar y vender" (Von Mentz et al., 1988, p, 67).

Así, el Soconusco, como muchas otras partes del país en la época, recibió la llegada de extranjeros dispuestos a "hacer las américas". Estos primeros viajeros que tenían como destino el Soconusco Chiapas, arribaban primero a Tapachula donde se encontraban las compañías deslindadoras, ahí se realizaban las compras de los terrenos y los trámites para obtener los permisos necesarios. Así lo recuerda en sus memorias Winfred Mahnken, hija de uno de estos finqueros cafetaleros de la zona del Soconusco:

Mi padre, Frederick Mahnken, ciudadano americano descendiente de alemanes y holandeses, llegó a Tapachula a finales del siglo XIX, porque había leído en un periódico de San Francisco, California, que una compañía vendía terrenos baratos en Chiapas. Salió desde San Francisco con destino a Puerto Ángel, donde conoció a un alemán que tenía una finca de café y lo invitó a visitarla. Mi padre que jamás había visto una mata de café, se enamoró de los cafetales desde ese instante (Mahnken,1993:15).

Posterior a la migración norteamericana, la compañía inglesa Chiapas Land Colonization se encargó del deslinde las tierras del estado. Así, debido el establecimiento de otras compañías deslindadoras y porque la disponibilidad en las tierras de Guatemala había menguado, los alemanes con fincas cafetaleras en el vecino país comenzaron a invertir en el Soconusco, contando con la experiencia necesaria y la más novedosa tecnología para el cultivo del café.

Por tanto, desde entonces, hasta la actualidad, el café se convirtió en la principal producción de la zona. Ésta se desarrolló de dos formas esencialmente distintas: la producción agroindustrial o a gran escala, por una 
parte, y por otra, la producción a pequeña escala, que era básicamente familiar, llevada a cabo en los ejidos y pequeñas propiedades de la zona.

Lo anterior, construyó una dinámica particular de interacción entre ambos tipos de productores, (a veces de disputa, otras de camarería), lo cual, consolidó una geografía cafetalera regional particular y un tejido de redes sociales locales, sobre lo cual ahondaré a continuación. A través del testimonio de un trabajador de la finca La Fortuna, que se encuentra localizada en Escuintla, Chiapas.

\section{Mi vida en la finca La Fortuna: "entre la verdad y mentira esto es más o menos lo que pasó"}

Yo llegué a la finca La Fortuna en cincuenta y tres y salí de ahí en 1958. Antes, llegaba sólo como comerciante, pero no establecido. Establecido estuve como siete años. Siempre vendí ropa, ropa de trabajo: pantalones, camisas, ropa interior, calcetines, camisetas, ésa era mi venta. La venta ahí es el sábado y el domingo. El sábado de las tres, que están pagando, a las ocho. El domingo ya no es la gente que vive ahí, sino los de los ejidos. Ellos están llegando a las seis. Los que no se emborrachan, a las diez se regresan a sus casas. Así era la situación ahí en La Fortuna.

A nosotros ahí nos llamaban los paracaidistas, porque no éramos trabajadores de la finca; nosotros estábamos en un mercado, una galera, ésa era el mercado. Yo tenía un puesto y lo hice sastrería. A mí ahí me toleraron casi diez años. Ya por último sí nos avisaron que desocupáramos, que nos daban un mes para desocupar, porque ahí iban a construir la casa grande, la casa del patrón. De ahí me salí yo y me fui a comprar café a Madero. Pero cuando, por ejemplo, trabajé la sastrería, llegaba tu abuelo y yo le tomaba medida y hacia su pantalón y se iba. Mis clientes eran 
principalmente los trabajadores y los ejidatarios, que llegaban a venderle café a la finca. Por ejemplo cuando a Madero le dieron las parcelas (en octubre les dieron la tierra y en noviembre comenzaron a cosechar), como no tenían pulpero para quitarle la cáscara a la uva y tampoco tenían patios se lo vendían a $\mathrm{La}$ Fortuna, porque como el terreno expropiado era de la finca $\mathrm{La}$ Esperanza, pues ellos no les iban a comprar café. Entonces, era un mundo de café, porque La Esperanza era más grande que La Fortuna, tenían treinta caballerías y Fortuna tenía veinte.

La finca estaba ubicada, o está, en un lugar muy bueno, porque es un lugar comercial. Llegaban de San Antonio Miramar, de Hoja Blanca, de Miguel Alemán, de Bandera, de donde quiera, era como un centro comercial. Ahí los ejidatarios y rancheros se surtían de lo que iban a comprar y se regresaban y había tienda de raya. La tienda de raya ya no era de raya porque ¿sabes tú qué es la tienda de raya? La pone la finca y ahí va a comprar el trabajador, si no hay dinero, le dan una ficha y con eso les despacha el tendero. Y cuando les pagan les descuentan. Pero cuando yo llegué ya no era tienda de raya, era una tienda normal.

\section{De galleras acasillados y chamulas}

La gente que vivía ahí era de dos categorías: la gente de gallera [jornaleros agrícolas temporales guatemaltecos o chiapanecos de la región de los Altos de Chiapas] era la más bastante y la gente de rancho (allá le llaman rancho al pedazo de cuarto de madera que le da el dueño de la finca: "aquí vas a vivir, aquí puedes ocuparlo") esos son más pocos. Esos son los acasillados que están estables. Los de gallera, en cambio, esos se mueven, nomás llegan en tiempo de cultivo, o en tiempo de cosecha. La finca trabaja con 
tres mil gentes y en tiempo muerto con mil gentes. Porque la finca tenía un terreno de veinte caballerías (una caballería son mil cuerdas, una cuerda tiene veinticinco metros cuadrados. Así que veinticinco metros cuadrados, esos es una cuerda y mil cuerdas una caballería, y la finca tenía veinte mil cuerdas).

El casco de la finca era el centro y a $8 \mathrm{~km}$ estaba la otra orilla donde terminaban los cafetales. Así que el que iba a trabajar a cortar café se iba de madrugada con candil o con lámpara de batería, ahí se iba alumbrando, para llegar allá a la hora que empieza a aclarar, para ponerse el canasto y empezar a trabajar. La gente de cultivo más lo hacían los acasillados. Había quienes trabajaban por día, porque no eran buenos para el machete, la gente que sí era buena para el machete trabajaba por contrato. Decían al capataz "deme cien cuerdas" y ellos se lo echaban en una semana. Trabajan bastante, eran prácticos.

En cambio, la vida ahí de los chamulas es diferente, hasta con la del guatemalteco. El chamula se duerme tirado en el monte. No anda viendo nada. No es delicado, come lo que tenga. Recuerdo que mataban las ratas grandes que andan en las matas, le quitaban las tripas y las metían a asar. Ya bien asada se la comían. El guatemalteco es más delicado. Ése no, a ése no le gustan las fincas grandes porque hay que madrugar y hay que cargar kilómetros para llegar al surco y luego, cargar hasta los recibidores. En cambio, en los ranchos a pocos metros está el surco y, además, a veces cuando no quieren hacer fuego se vienen a la casa a desayunar. En el tiempo que están cortando verde ${ }^{6}$ buscan el

${ }^{6}$ Hay varios "cortes" de café, el primer corte es de café maduro y se considera el café de primera. El segundo es el corte del grano verde. Por esto, los "cortadores" reciben salario a destajo; es decir, según la cantidad de grano cortado al día en mam cha'x o 
rancho porque comen tortilla caliente, tamalitos y todo eso, y en la finca les entregan la tortilla caliente en la mañana, pero cuando llegaron al surco está fría y como es de maquina ya va en pedazos (en el morral se quiebra y se hace pedacitos). Además, el frijolito los cocineros no están escogiendo, que no lleve piedra o basura; porque va del costal al perol. Y como echan bastante frijol, se coce con todo y basura y a veces mastican una piedra y se astillan una muela y a veces en el café o en el frijol se van los ratones "qué te quejas, si ya está cocinado" así dicen y los chamulas no se quejaban, el guatemalteco sí se quejaba. "oiga usted el frijol nos dan poquito, no nos dan suficiente pozol", con el planillero, se quejaban, porque el dueño ni se está.

El planillero era el que recibía el café en el beneficio húmedo. Cuando llega la gente que llega a pedir trabajo lo forman, ahí en una ventanilla le toman su nombre.

— ¿Cómo te llamas?

— "Fulano de tal". Buscan qué número le toca. -Te tocó el número 85-.Con ese cartón le van a contar el número de café que pizca.

-Éste es tu número, grábatelo. Cuando yo te pregunte que vengas aquí a checar, me dices tu número-. Es más fácil checar por número que por nombre

—A ver, tu número. ¿Fulano de tal?

-Sí.

— ¿Tú hiciste tantas cajas?

q'an, es decir, verde o maduro. La unidad de medida utilizada es aún "el quintal" de origen colonial, (47 kilos).

Revista Cadernos de Estudos Sociais e Políticos, v. 5, n. 9, jan-junho 2016 
—Sí.

- Correcto, aquí está tu paga. Ya puedes irte. Si te hace falta vienes a reclamar

—No hace falta, está completo.

Por eso, con ese sistema, en una hora pueden pagar doscientas gentes. Así que en cuatro horas pagan mil gentes. En la oficina, hay contador, administrador, que son los que controlan la oficina. A parte están asignados algunos trabajadores acasillados ya viejos, que son caporales. Caporales hay de varios tipos: caporal de primera y de segunda. Los caporales de primera entran a las bodegas les entregan herramientas para poda, para limpia, azadones para hacer tomas para ir a limpiar almácigos y todo eso; serruchos para la poda. A parte del machete y se los apuntan a los trabajadores, y cuando se van a venir o ya se terminó de trabajar. El trabajador tiene que entregarlos y le dan una constancia a él de que ya lo entregó y si no, se lo cobran.

Y es que había mucha gente trabajando en las fincas. Llegaban de la tierra fría, de Motozintla, Porvenir, Siltepec. De muchas partes, llegaban a trabajar a Fortuna o a cualquier finca. Llegaba gente de esas partes, cuando yo llegué trabajaba con pura gente de Chamula. Ya después no, porque llegaba mucha gente brasera de Guatemala. Y ya no llegaban tanto los chamulas. Porque el chamula es bueno para la carga, pero para trabajar la cuestión de la pizca no tanto, porque no es muy ligero; el guatemalteco es mejor, tiene más agilidad. Llegaban chamulas pero ya por su voluntad ya no como antes, que los mandaban a contratar desde San Cristóbal, que un contratista los iba a traer de los parajes. En ese tiempo que llegué yo ganaban 4 pesos como jornaleros, del diario, podrilleros, le dicen ahí, la cuerda de café son dos cuerdas 
por tarea les pagana 4 pesos, a principio de la década de los cincuenta y ya a mediados de los cincuenta les pagaban 7 pesos y entrando los sesenta ganaban 10 pesos, por la tarea o por el día. Ahorita quién sabe, deben ganar unos 100 pesos $^{7}$, con eso vivía la gente y bebían.

En el sentido de este testimonio, cabe mencionar que la creciente industria cafetalera en la región, durante principios del siglo XX creó una fuerte demanda de manos para pizcar, cajetear y sembrar el café. La cual, no se daba abasto con la mano de obra ofertada localmente, puesto que "se requerían entre 30 y 40 mil trabajadores temporales en cada cosecha, unos 12 a 15 mil se contrataban de Motozintla, Comitán y las comunidades de los Altos de Chiapas" (Von Mentz et al., 1988:266). Y "Mientras que los trabajadores guatemaltecos venían por su propia cuanta, a los peones mexicanos había que engancharlos. Para ellos, los grandes empresarios contaban con habilitadores que residían en las respectivas regiones" (Von Mentz et al., 1988:266). Estos "habilitadores" eran por lo general "ladinos". Es decir, mestizos de San Cristóbal de Las Casas, que enganchaban a indígenas de los Altos de Chiapas, muchas veces con engaños, ya que se aprovechaban las fiestas de los pueblos, cuando los indígenas se encontraban apremiados de dinero. Así, "para que los cafetaleros de Soconusco obtuvieran la mano de obra para sus fincas en la cantidad y tiempo necesario

de octubre a febrero tenían que adelantar dinero a los trabajadores a cuenta de su trabajo a desempeñar (...) por su servicio, los enganchadores retenían hasta la tercera parte del dinero adelantado a los trabajadores" (Grollorá, 1995:199). Una vez “enganchados”, los indígenas eran

\footnotetext{
${ }^{7}$ Al tiempo del trabajo de campo (2013) generalmente se pagaba a los jornaleros noventa pesos por día más tres comidas.
}

Revista Cadernos de Estudos Sociais e Políticos, v. 5, n. 9, jan-junho 2016 
transportados a San Cristóbal hasta que se reunía un número suficiente de personas para ser llevadas al Soconusco.

El viaje duraba aproximadamente ocho días y se realizaba en condiciones insalubres y desfavorables. Este sistema de enganche, en el cual coludían también organismos municipales, creó un lucrativo negocio que surtió de mano de obra barata a los grandes productores de café. Muchos indígenas enganchados en los altos llegaron a las fincas del Soconusco, para morir finalmente en esas inmensas plantaciones, que fueron el escenario de diversos acontecimientos, en donde confluyeron todo tipo de historias, muchas veces con el sonido cantarín de una marimba de fondo.

\section{Fiestas y bailes en La Fortuna}

Ahí mismo en la finca había un expendio de cerveza que se llamaba "La Clínica", que era de la finca y medía unos dos metros cuadrados. Ahí metían 50 cuartones de cerveza, enfriadores y todo eso. El chamula al inicio no tomaba, pedía una cerveza, como veía que los otros lo saboreaban. La pedía y la escupía, porque amargaba, después se iban acostumbrando ¡imagínate tres mil gentes! ¡Todos tomando! Y el caporal y la policía que eran los acasillados, controlaban la borrachera y los bailes.

Había grandes bailes en la escuela. Los organizábamos nosotros, los paracaidistas, que éramos los más "lavaditos". $\mathrm{Y}$ a veces los mismo trabajadores organizaban la fiesta, por ejemplo los de Bejucal ellos mismos llevaban una marimba y cada sábado hacíamos baile y habían tres señores que ponían venta de cerveza ilegal en el patio de la escuela, y cada clientes llevaba 200 cartones y en un baile de las ocho de la noche para las dos o tres

\footnotetext{
${ }^{8}$ Expresión usada coloquialmente para referirse a ser mestizo.
} 
de la mañana se iban los 600 cartones de cerveza era muy tomadora la gente. Porque no había otra diversión.

Cuando había fiesta con marimba de fuera era que celebrábamos año nuevo o navidad, cuando llegaban marimbas de Huixtla o Tapachula. Llegaban también de otras fincas como de la Esperanza, llegaban unas marimbas, como "la corona de Tapachula", muy buena marimba.

Y claro que había más cosas. Las mujeres prostitutas, por ejemplo, llegaban de Villa Comaltitlán y de Huixtla. Porque había personas que se dedicaban al trato de blancas, llevaban diez mujeres que llevaban y hablaban con la finca, y la finca les daba un lugar. Ahí, por ejemplo, en el campo de futbol, ponían cerveza y hasta baile hacían. Los patrones los dejaban porque estaban llenas las galleras con hombres solteros. Se estaba tres días y ya nomás. La gente también ahí se casaba y eso.

Don René: de paracaidista a comprador de café y de su amigo Ofelio Jovel

Es bonito trabajar con las fincas. Pero me salí de ahí y me volví comprador de café. De ahí de La Fortuna me llevé 12 mil pesos de capital y con eso me fui a Villa Comaltitlán y compré cinco caballos y ya me fui a comprar café a Madero.

La finca nos daba permiso de amarrar nuestros caballos, a veces le vendíamos a la finca cuando les faltaba para exportar. Si nos convenía se la vendíamos. A veces no le gustaba porque el café que vendíamos era secado en patios de tierra y no les gustaba a ellos, pero cuando era muy necesario, lo tenían que comprar, 
cuando no, no. Comprando café, recorrí Madero, que tiene 70 o 100 hectáreas con 200 cuerdas de café, pero salíamos a Miguel Alemán, a Cabañas, Hoja blanca, hasta ahí llegábamos a comprar café. Cuando terminaba la compra de café en esa zona nos veníamos al Zapote, ahí entrabamos a comprar café a Sata Emilia y hasta San Juan Panamá, Vega de Juárez, que son los cafetales de San Antonio Miramar, porque donde ellos están solo tiene sus casas, su café está en las cañadas. Hasta ahí llegábamos a comprar café, terminando nos íbamos a Siltepec, porque por allá la compra termina en enero. La furia de la compra es de noviembre a enero. Terminábamos en Siltepec, donde teníamos una casa para almacenarlo cuando juntábamos 100 o 200 bultos, alquilábamos carros para bajarlo a Huixtla. Ahí vendíamos nuestro café, en marzo termina la compra de café donde quiera y yo agarraba mis bestias y la llevaba a Villa Comaltitlán y me iba Comitán. Ahí viajaba yo a la costa con aguardiente y calzado. Le vendía yo aguardiente a Escuintla, Huixtla, Acapetagua, venia 1500 litros. Y compraba con los Pedrero a 4 pesos el litro y lo vendíamos a 7 pesos en la costa; además llevaba calzado de campo, calzado minero y subía a las fincas y lo vendía por docena, y ganaba mil o dos mil pesos extra. Antes de irme a Comitán pasaba a Tuxtla Chico y compraba chocolate y lo vendía yo muy bien en Comitán y de ahí salían mis gastos de regreso.

Luego, me volví comerciante, pero, siempre recuerdo mi vida en las fincas. Y a toda la gente que conocí ahí. Los acasillados, por ejemplo, eran de varias partes, había gentes que cuando yo llegué

\footnotetext{
${ }^{9}$ Julio de la Fuente en sus informes de 1954-1955 documenta la "guerra del posh". En la cual refiere, por una parte, las prácticas monopólicas de los Pedrero Argüello empresarios del alcohol-y sus contubernios con el gobierno chiapaneco; por el otro, reporta el sistema clandestino de producción y venta de aguardiente, promovido por las propias comunidades indígenas como respuesta a las prácticas monopólicas. (Véase: De la Fuente, 2009)
}

Revista Cadernos de Estudos Sociais e Políticos, v. 5, n. 9, jan-junho 2016 
ya estaba ahí. Un amigo, estuvo ahí cincuenta años. Llegó de chamaquito, dice que llegó de cinco años, lo llevó un su tío porque era huérfano, ahí estuvo trabajando con el tío. El tío murió pero él se quedó chamaco grande, y ahí trabajó cuarenta y cinco años. Empezó como limpiador de almácigos y terminó de mecánico y chofer. Y cuarenta y cinco años de trabajo y lo despidieron por la edad. Le dijeron

—Usted don Ofelio, ya no va a trabajar en la finca

— ¿Y por qué? ¿dónde voy a trabajar, pues?

—No sé, aquí la finca lo va a liquidar.

— ¿Y cuánto me va a dar?

-10 mil pesos

— ¿¿Por 45 años de trabajo cree usted que está bien 10 mil pesos?! Sólo su contador gana eso en un mes, ¿y usted no me puede dar dos meses de sueldo del contador? Póngase la mano en el corazón-Así que le dieron16 mil pesos.

—Te vamos a dar 16 mil pesos, y si no, demándeme.

— ¿¿Cómo lo voy a demandar si usted tiene millones de pesos?!, y usted me está corriendo y no tengo nada... ¿Prefiere darle dinero a la autoridad, y no dármelo a mí? Si usted dice que 16 mil pesos me va a dar, ni modo, con eso me voy a ir. Pero grábeselo, cuando se lo esté llevando el carajo, acuérdese de mí y de lo que me está haciendo ahorita.

—Ya vete, sáquenlo, ¡sáquenlo!- dijo el patrón. Y lo sacaron.

Él habló con el administrador 
— ¿Dónde te vas? A Motozintla, allá están mis hijos, mi mujer ya murió.

- Compón tu cosas, que las carguen y te vas mañana a las cinco de la mañana.

Ahí se fue. Acaba de morir en Motozintla, tenía 81 años. Buena persona. Éramos de la misma plebe, jugamos fútbol, tomábamos trago, todo eso. Después, ya más viejo, trabajaba como mecánico. Ése era mi amigo, Ofelio Jovel y ésa fue su vida (don René Pinto, 85 años, Motozintla, entrevista en Tuxtla Gutiérrez por Claudia Morales).

Considero que el testimonio anterior, nos da un panorama de los actores que constituían una finca, en particular, una de las más grandes y productivas de la zona. Ya que la finca La Fortuna es hasta la fecha un referente para las localidades del lugar. Y parte fundamental de su historia, ya que era el punto en el cual se socializaba y comerciaba. Un lugar que fungía como centro de interacción y organización social. El testimonio anterior recrea de primera mano la vida en las fincas, espacios en los cuales se gestaron historias y procesos políticos y sociales.

\section{Peones y finqueros cultivando café}

Teniendo en cuenta el testimonio anterior, así como la bibliografía desarrollada con relación a la producción de café en las fincas del Soconusco, no ahondaré más con relación a los diversos procesos que trascurrieron en dichos espacios. Sin embargo, debo resaltar que el sistema de producción del 
café entre pequeño productor y finquero era y es aún hoy día, evidentemente, distinto.

La forma en que trabaja la finca es de dos formas: el beneficio seco es donde están las secadoras, la retilla, la separadora, las pesas, las máquinas para costurar los costales. Ése es el beneficio seco; por otra parte, está el beneficio húmedo, que es donde llega el café en "uva", le dicen ahí. Llega en costales o cajas y lo meten a unas maquinarias que se llaman pulperos, que son unos discos grandes con una zaranda, que le dicen, donde cae ya el café molido. Lo tritura el disco y le quita la cáscara, y queda el puro grano de café y, entonces, al caer el café, la pulpa cae en la zaranda que con un movimiento, que llaman oscilatorio, el grano cae a una toma y se va a un tanque fermentador. Ahí se queda tres días y ya que está fermentado lo lavan y la cáscara la misma zaranda la va sacando a la orilla y ésa ya se va, hasta 400 metros hasta donde están los arroyos o ríos para que se la lleve. Cuando tienen patios, lo secan por patios, grandes patios. Ahí meten 100 bultos, por ejemplo de café, eso serían 4 mil cajas de café.

Los dueños de la finca, cuando yo llegué era un francés, se llamaba Ernesto Suiri. Pero, al poco tiempo, se casó con una señora en México, que era de Monterrey. Y se casó con él y se fue a la finca. Al señor lo mataron ya salió la versión que la señora lo había mandado a matar para quedarse con la finca. Y bueno, cuando el señor murió llegó un hijo de la señora que era ingeniero en electrónica, pero en el DF trabajaba de taxista, eran pobres, pues. Tal vez clase media, y cuando llegó ya la finca era de la mamá y el señor, como era ingeniero en electrónica, modificó todo: del beneficio seco sacó a la gente del patio y metió maquinaria. En los patios donde se lava el café, en lugar de lavarlo en tanque con palas y todo eso, hizo una toma ancha y ahí salía el 
café fermentado ya con suficiente agua y al llegar al patio había un deposito como tanque. Ahí había una turbina, entonces ahí caía el café y lo lavaba, en un ratito ssshhh ya estaba saliendo el café limpio al patio. Ahí un "tractorcito" lo juntaba (hablo de un patio que era de una hectárea). Ahí se hacían los granes pilones y ya traían una máquina como aspiradora. Metían una manguera corta como de 4 pulgada y otra larga y se iba hasta las secadora, y lo metían a la secadora que era movida por una compresora enorme que le daba calor a cinco secadoras y cada secadora le cabían 120 bultos de café y cada doce horas salía una partida de café de 600 bultos y entonces, cuando hicieron todos esos cambios, se acabó la gente que trabajaba en los patios, quedaron 4 o 5 para manejar los aparatos y en el beneficio seco sólo con mujeres. Las mujeres de los trabajadores acasillados eran las que llegaban a escoger el café.

Llegaban 25 mujeres de un lado y 25 del otro lado y pasaba una banda por la que escogían el café. Y por 20 metros ya estaba limpio, porque eran 50 manos que escogían y caía el grano en un costal donde había una gente que estaba cambiando los costales.

El grano bajaba a la maquina "costuradora" y wassshhhhs, lo sellaban y lo llevaban. Cuando metieron maquinaria cortaron a esa gente y los sustituyeron por una máquina que llaman separadora. Ahí caía el chorro el café seco y ahí separaba toda clase de café: el quebrado, el manchado, un café grande que llaman la concha el caracol, el café de primera y el café de exportación. Ahí lo empaquetaban ya sea para que se quedara al país o para extranjero. Las exportaciones eran por barco, lo llevaban al tren y de ahí se iba a Veracruz y de ahí lo dejaban en bodegas que lo llevaban a Francia, Inglaterra, a donde sea. Por eso trabajaban 3 mil gentes en la finca, porque entraban hasta 4 mil bultos de café, 
diario, diario. La finca era un pueblito entero el que trabaja (don René Pinto, 85 años, Motozintla, entrevista por Claudia Morales en Tuxtla Gutiérrez)

Sin embargo, tanto en las fincas como en las pequeñas propiedades, hasta la fecha, en tiempos de cosecha se distribuyen los trabajos por beneficio. En el beneficio seco se emplean: caporales, recibidores y planilleros. Mientras que en el beneficio húmedo $\mathrm{y}$ en los patios, los trabajos son: desvanadores, despulpadores, lavadores, patieros y envasadores. Empero, las fincas, como se mencionó, se realizan estas actividades con personal acasillado y jornalero. Por su parte, las pequeñas propiedades las realizan en familia y con una porción pequeña de trabajadores contratados.

Aunque en la actualidad existen algunas cooperativas, los ejidatarios siguen siendo dependientes de la tecnología de las fincas, que cuentan con la infraestructura necesaria. Asimismo, desde siempre, los ejidatarios han acudido a ellas para realizar diversas actividades, ya que muchas veces fueron peones de las mismas, y recurrían a ellas asiduamente. Lo anterior, relacionado con la historia de su fundación. La cual intentaré resumir a continuación.

En cuanto a las localidades que visité, tuvieron dos diferentes procesos para la dotación de la tierra: algunos pobladores llegaron de Guatemala a trabajar a las fincas cafetaleras $\mathrm{y}$, posteriormente, se asentaron en las tierras nacionales no ocupadas (sin disputa alguna con los dueños de las fincas). "La mayoría de los campesinos guatemaltecos llegaban a las fincas de Soconusco por su propia cuenta, provenían de las comunidades fronterizas y del departamento occidental de San Marcos, aunque hubo personas del altiplano 
[...]" (Von Mentz et al., 1988: 273). Estos campesinos sin tierra en Guatemala o muy poca para subsistir "se fugaban de las fincas para buscar nueva vida en Chiapas o Belice. El régimen de Cárdenas tenía como propósito repartir tierras a quien las trabajara; en el caso del Soconusco eran peones encasillados o pequeños rancheros de origen Guatemalteco" (Von Mentz et al., 1988: 273).

Yo desde chico estuve trabajando en el café, viera que antes aquí no había carretera, ni aquí para abajo, vaya que un mi cuñado que fue comisariado, estuvo luchando para que se hiciera la carretera, y viera que aquí no había mucha gente, nomás habíamos como 30 ejidatarios y sólo eso. Ya nomás no había, ya vinieron los demás aquí porque había mucho terreno, la entrada eran doce pesos. Ya venían acá y les daban su pedacito de terreno y ahí se iban. Allá de aquel lado, cuando no había gente unos agarraron casi una caballada de terreno, terrenal agarraron. Esos fueron vivos, agarraron terral de achingo. Lo que garró mi papá fueron nomas 300 cuerdas, 12 hectáreas (don Eufracio Pérez Roblero, 80 años, ejido Brasil, Huixtla, entrevista por Claudia Morales).

Un segundo grupo, invadió tierras de las fincas y posteriormente, se conformaron como ejido.

Yo tengo 82 años. La raza de nosotros es que somos comitecos, mi papá que vino allá de su tierra como que huyendo, en ese tiempo había guerra les llamaban "los villistas", "los mapaches"10.

${ }^{10}$ El movimiento armado Mapachista fue una reacción local de la agitación de la época revolucionaria, se basó en un ejército de civiles conservadores organizado por las élites dominantes de Chiapas, para repeler el de todos por el avance de las fuerzas Carrancistas durante la Revolución Mexicana (1910-1920). Por medio del Acta de Canguí (1914), el movimiento Mapachista se constituye como grupo opositor a las fuerzas de ocupación del General Carrancista Jesús Agustín Castro. Tiburcio Fernández Ruíz era el líder del movimiento. Su lema era "exterminar el mentado 
Y si te agarraban, les rajaban los pies y les echaban limón, los colgaban. En ese tiempo fue que se huyeron mi papá, sus hermanos y mi papá, se echaron a las fincas a trabajar aquí a este lugar. Mi papá ya quedó ahí en Motozintla un rato, con una familia de los Pivarales, mi mamá se llamaba Juana Pivaral. Pero nos sacó de allá mi papá a las fincas, porque más nos criamos en las fincas, yo no fui a la escuela, no aprendí a leer. Sólo anduve en las fincas.

De repente mi papá ingresó a Francisco I. Madero, donde estaban peleando las tierras, pero a mi mamá no le gustó. Mi papá siempre en las fincas y en las fincas, ahí crecimos. Ahí era puro trabajo. Y ya mi papá supo que aquí estaban dando ingreso y nos venimos para acá, y aquí ya tiene años que estamos. Tuve mis doce hijos. Yo me casé cuando mi esposa tenía14 años y yo tenía 20, y empezamos a trabajar: mi papá y yo, y a ganarnos el pedacito de tierra que tenemos.

Aquí pertenecía a Fortuna, porque era de la finca, y no quería que nos metiéramos eran 60 hectáreas de montaña que poseímos, hicimos una gestión, estuvimos gestionando y le quitamos 30 hectáreas de café. Hubo muertos. Hubo balacera con nosotros, por parte de la finca. A mí me balearon. Fui a la prisión y me balacearon, por ganar el pedacito de tierra. Y a mí ya no me tocó más, le tocó a los que no tenían. No me dieron más de lo que ya tenía. Un poquito de terreno.

El mero de la finca dicen que estaba seguro con el gobierno y no daba la tierra y hasta la fecha. Pero, nosotros echamos guerra con el mero rico, mandó a matarnos: mandó soldados y gente armada,

constitucionalismo y sus leyes odiosas y regresar al Estado su soberanía y su régimen constitucional". Véase (Benjamin, 1995)

Revista Cadernos de Estudos Sociais e Políticos, v. 5, n. 9, jan-junho 2016 
pero nosotros no nos dejamos, echamos bala con ellos. Yo me balacearon en mi pescuezo, pero gracias a dios estoy vivo. Y mi papá que era andariego aquí murió, también mi mamá, sólo nosotros quedamos vivos. (don Alfredo Barrios Pivaral , 81 años, ejido Cuauhtémoc entrevista por Claudia Morales).

Sin embargo, la constante entre ambos grupos es que conocieron el proceso de cultivo de café y se finalizaron con el cultivo del aromático, al ser peones de las fincas cafetaleras. Por tanto, un momento importante para las localidades de la sierra es la "lucha por la tierra", o la dotación de ésta. Ya que configuró el desarrollo de un sistema de vida, relacionado con el trabajo agrícola. En todos los casos, la tierra les permitió dejar de ser peones para convertirse en propietarios.

Yo me llamo Rodrigo Pérez Roblero, tengo 83 años de vida, 83 cumplidos. Nosotros desde el día en que me uní con mi esposa, ya somos casados, nos huimos, me la robé y todo eso, y aquí nos venimos a meter, con los compañeros que estaban sufriendo mucho, era el año de 1946, parece. Desde entonces, estoy juntado acá y luchamos las tierras al rico. No estaban seguras las tierras, estaban falsas, luchamos las tierritas y las logramos ganar. Aquí es el ejido Cuauhtémoc municipio de Motozintla, y acá nos quedamos, acá nos “afamiliamos". Comencé a trabajar materialmente para mis hijos, porque no nos tocó mucha tierra. Nos tocó como 40 cuerdas a cada uno, comencé a trabajar por otra parte, no me atuve al café. Tuve mis mulas y todo eso, así logré sacarlos a mis hijos de aquí: les compré sus terrenos, todos están fuera. Solo estamos yo y mi estimada compañerita, mi esposa (don Rodrigo Pérez Roblero, 83 años, ejido Cuauhtémoc, entrevista por Claudia Morales Ramírez). 
Como mencioné al inicio este proceso no fue abrupto, sino un largo proceso violento que transformaría el rostro de campo en Chiapas en el siglo XX. Las relaciones entre finqueros $\mathrm{y}$ pequeños propietarios o ejidatarios, continuaron siendo conflictivas por años venideros. Sobre todo, porque, pese a que habían obtenido la tierra, los agricultores no contaban con la infraestructura que les permitiera secar y transportar el grano. Para esto, dependían directamente de las fincas. "A lo largo de los años treinta los finqueros cafetaleros buscaron cuanto medio tenían a su alcance para contrarrestar el movimiento agrarista de los campesinos acasillados y pequeños rancheros, que se establecieron en las márgenes de las plantaciones y trabajaban en ellas durante las cosechas y limpias de café, los métodos variaron desde ventas de porciones de fincas hasta la represión de líderes agraristas" (Von Mentz et al., 1988: 286).

Muestra de esto es el memorándum enviado a la Secretaría de Gobernación con fecha de julio 18 de 1940:

El comité ejecutivo agrario de la finca el Retiro, Chis., se dirige al Señor Presidente de la República quejándose de que el señor Werder Meyer, de nacionalidad alemana, tiene comisionados entre otros, a los Cc. Eustaquio González y Froylan Ruiz para que asesinen a los miembros del citado comité por haber resuelto su expediente de solicitud de dotación de tierra, en primera instancia ese gobierno y encontrarse ahí el ingeniero que deberá dar posesión de las mismas, propiedad del citado señor Meyer. Pide la mencionada agrupación que en vista de lo expuesto se considere al referido señor como extranjero pernicioso y le sean aplicadas las 
sanciones que establece el artículo 33 constitucional (Archivo General de la Nación) ${ }^{11}$.

Gran parte de los ejidos continuaron peleando tierras a las fincas de 1939 hasta 1970. Sin embargo, aún en 1994, continuaron las invasiones y las disputas, esta vez a la finca San Luis, filial de la finca Fortuna. Esta invasión fue comandada por ejidatarios de Hoja Blanca, quienes junto a los recién llegados que venían la posibilidad de hacerse de tierras, entraron a la finca armados justo antes de la cosecha de 1994-1995. La finca Fortuna, tuvo intentos de negociación entre los dueños y los invasores, pero al no llegar a ninguna acuerdo, el movimiento fue aplacado con el mismo mecanismo de antes: la represión.

Faltaba poco para cosechar, había harta cuerda de café listo. Se sacaron varios bultos. Veníamos a cosechar nosotros acá, trajimos nuestra gente a cortar el café, precioso que estaba, bien tendido...Pero ya ves la gente, se pusieron avariciosos y ya no salió bien, porque la señora [la dueña de la finca La Fortuna] dijo que nos daba otra finca, la de Buenos Aires, pero no quisieron, querían San Luis, y necios, y necios. Y luego, su problema del líder es que era bolo, bebía mucho. Decían que él era de Guerrero y vino acá a organizar a la gente. Pero era bien bolo, bajaba a Belisario caminando y en una de esas, la señora lo mandó a matar, allá lo enterraron por Manacal (don Efigenio Morales Carbajal, 70 años, Hoja Blanca, entrevista por Claudia Morales Ramírez).

Estas disputas contantes por la tierra configuraron en gran medida no sólo la geografía de la zona, sino que también formaron parte central de la vida de

${ }^{11}$ Archivo General de la Nación/ Departamento de gobierno. Sección I. Mesa II. Expediente 2/362(43)/4. 
una generación de campesinos. Ahora bien, en cuanto a la producción de café, en las pequeñas propiedades y ejidos cafetaleros, a los márgenes de las extensas plantaciones, la producción era casi siempre familiar, aunque también requería de mano obra externa. Para esto, se contrataba a trabajadores guatemaltecos, que vivían en la propiedad y a quienes se les pagaba a destajo, y tres comidas. Aún en la actualidad, pese a que cada día en menos número, estos trabajadores continúan llegando, con el mismo sistema de contratación de antaño.

No obstante, debido a que en tiempo de cosecha la mano de obra no era suficiente, se requería también de la participación de toda la familia en las labores domésticas. Las mujeres, debían alimentar a los trabajadores y, por su parte, los hijos pequeños debían vigilar a los jornaleros durante el corte de café "para que no lastimen las matas". De igual manera, los jefes de familia realizaban otras actividades, eran comerciantes de bebidas alcohólicas, arrieros, o trabajadores asalariados de las fincas vecinas.

Yo, por ejemplo, no nací aquí. Nací en una propiedad que se llama El Retiro municipio de Motozintla, ahí trabajábamos, pero ya después, mi papá estaba peleando este terreno y nos venimos acá, nos venimos a luchar, pues, y yo aquí me crecí, vine muy pequeñito, aquí no había café era pura arboleda de pacaya, pero ya después se fue destruyendo cuando el terreno se ganó, se dividió y cada quien, pues. Y ya se fueron botando las arboledas no dejaron una mata para recuerdo, los árboles de toronjil habían muchos, eran palos grandes. Pero, no los dejaron, no los cuidaron. En ese tiempo que estaban repartiendo los pedacitos, como yo era pequeños, no me dieron terreno, le dieron a los que llegaron aquí antes, a mi papá. Nos dedicamos a sembrar café. Pero, antes yo me fui a trabajar a las fincas, en La Esperanza, en la finca de La 
Paz, me fui a trabajar a la finca Santa Isabel porque nuestro café estaba pequeñito. En La Esperanza trabajé como arriero. Me vine acá cuando mis padres murieron (don Sergio Roblero, 61 años, ejido Cuauhtémoc, entrevista por Claudia Morales Ramírez).

Lo anterior es importante, ya que esto no sólo ha sido parte de la historia local, sino central en la dinámica de constante disputa entre el pequeño productor de café de la sierra del Soconusco y los grandes capitales de la agroindustria respaldada por el poder gubernamental en la región. Además, en fechas recientes se han comenzado a establecer empresas mineras lo cual ha incrementado la tensión en el lugar.

Los interlocutores entrevistados, ahora ancianos, enfrentan de nuevo las siempre latentes disputas, por lo cual, a continuación se analiza y describe el discurso recurrente entre la población anciana con relación a lo que consideran una amenaza gubernamental. Pues dicen sentirse directamente amenazados por las fumigaciones del programa Moscamed, (Programa contra la Mosca del Mediterráneo), y expresan que el pesticida afecta sus cultivos. Este discurso decidí tomarlo en cuenta, ya que considero que las narraciones de estos eventos, en apariencia paranoicas, son un lenguaje a través del cual expresan un sentido de amenaza y reconocimiento de la vulnerabilidad que enfrentan en la última etapa de su vida.

\section{Abelito González de León: "el gobierno nos quiere acabar"}

El hogar de Abelito González de León está ubicado como una de las zonas de riesgo de deslave. Según se indica en el mapa que cuelga de la pared de la caseta telefónica de la localidad Hoja Blanca. Por tanto, en caso de lluvias intensas, él y su familia deberían evacuar. Su hogar está en particular peligro ya que su propiedad se encuentra asentada junto a un río, que se oye

Revista Cadernos de Estudos Sociais e Políticos, v. 5, n. 9, jan-junho 2016 
chisporrotear hasta su cocina. Su casa es amplia y limpia, con paredes adornadas por las fotos de sus hijos y nietos.

Don Abelito es un hombre alto y fuerte a quién sólo faltan algunos dientes. Durante la invasión de parte de los ejidatarios de Hoja Blanca a la finca San Luis en 1994 (que se mencionó en el primer capítulo) don Abelito fue un líder importante en el movimiento y por su rol en este conflicto ahora es apodado "el comandante Abelito".

El comandante Abelito siempre usa un sombrero pequeño y ajustado y, a diferencia de su esposa, que casi no sale de la casa, a él se le puede ver todo el tiempo rondando la caseta, esperando una llamada o conversando con el resto de la gente que llega ahí, como él, sólo para pasar la tarde.

Durante las diversas entrevistas con don Abelito insistió en hacer énfasis en la teoría popularizada, tanto en Guatemala como en la zona del Soconusco, con relación a que las fumigaciones del Programa Moscamed (contra la Mosca del Mediterráneo) envenenan los cafetales hasta secarlos. Y que, por lo tanto, son responsables de la presente plaga de roya en la localidad. Esta teoría está muy generalizada igual que otras conjeturas con tintes conspiratorios con relación a la presencia de las mineras en la región.

Yo soy Abelito González de León de 1941 del 13 de enero, tengo setenta años ahorita. Tengo bastantes hijos: tengo once hijos. Todos trabajan fueran de acá, menos un mi muchacho que está acá con su esposa y con sus tres niños. Mis demás hijos viven en Escuintla, otro en Huixtla y los demás están en Estados Unidos. Yo no soy nativo de aquí. Pero tiene cincuenta años que vine acá soy de Vega del Rosario, municipio de Siltepec, de la familia Rivera. Vine aquí a trabajar y me casé. Éste era el terreno de mi mujer y ahora lo trabajo yo.

Revista Cadernos de Estudos Sociais e Políticos, v. 5, n. 9, jan-junho 2016 
El café lo trabajé bonito toda mi vida, hasta ahora que quedó sin hoja, por la roya, y ahora con la lluvia se puso verde pero no tiene grano. Y como hasta ahora, no hay ninguna solución, pues ahí le estamos echando ganas. Porque no se pueden sembrar otras siembras, un poquito de frijol, un poquito de maíz para comer. Desde un principio ha sido el café y no hay terreno vacante y se da uno cuenta que es por la fumigada del gobierno que se han muerto nuestras matas. Hasta mis palos de aguacate. Todo se ve que se muere. Y ésa es la razón por la que los cafetales están decaídos: por causa de la fumigada de parte del gobierno. Moscamed tiene una avioneta que pasa y tira ese líquido y eso afecta los cafetales $^{12}$.

El cambio que hay [después de la fumigación] es que cuando pasa la fumigada se nota que los arbolitos que uno tiene sembrados se empiezan a secar. Así comienza a secarse todo: algunos palitos de aguacate, de limón, de naranja se empiezan a pudrir y cuando uno los viene a mirar están votando la hoja. Hablamos en la junta general del ejido sobre la fumigación, pero ahora no podemos hacer nada sobre eso, sólo que hiciéramos un paro de mucha gente. Porque es el gobierno el que nos está amolando con la Moscamed. Le dije a un político la otra vez en [la localidad de] Belisario Domínguez, "ustedes están ganando buen billete y acá nos están amolando".

${ }^{12}$ El programa Moscamed (Programa contra la Mosca del Mediterráneo) inició actividades en 1977 consecuencia de la detección de un adulto de esta plaga que es una de las más devastadoras de la fruticultura a nivel mundial. En la República Mexicana no se ha extendido salvo por la zona limítrofe con Guatemala y su posible establecimiento causaría pérdidas de millones de dólares. Por esta razón México firmó un convenio con Guatemala en 1975 y posteriormente con Estados Unidos país que se adhiere al programa para prevenir erradicar la mosca del Mediterráneo en esta región. (Mendez Espinoza et al, 2006).

Revista Cadernos de Estudos Sociais e Políticos, v. 5, n. 9, jan-junho 2016 
Luego la junta antepasada vinieron dos muchachos y hablaron [con nosotros] en la junta general para ir en los arroyos buscando algo y querían llevar arena de cada río para hacer análisis y si resultaba bien su estudio, [si encontraban minerales] iban a volver a hablar con nosotros, pero antes que nada no les dimos permiso y se fueron. Ahorita lo que importa es conseguir almácigos de otras variedades de café porque necesito otras variedades de café que no sean borbón, ahí cultivé unas de corte bajo y ésas matas sí están bonitas. A ver cómo se pone el tiempo en adelante, más bueno o más amolado.

Por ahora nos dan el PROCAMPO una vez por año y ahí, asegún, una mínima por ahí. Me dan como 1300 pesos por hectáreas y me sirve para arreglar algo el café. Ahí le voy yo trabajando. Porque yo me siento más o menos macizo, viejo no. Para mi ser viejo sería una dicha. Llegar a unos ochenta o noventa años, eso sería una dicha. Pero a la vez, un sufrimiento, porque como está esta crisis, y los hijos que no están acá. Pero, Dios es el único que dirá hasta dónde llegamos. Yo más o menos me siento bien, porque aguanto trabajar galán, no me siento decaído, algunos dicen que ya de setenta años comienzan a decaerse uno. Pero creo que el ejercicio la verdad a mí me ayuda mucho. Yo no siento la edad.

Aunque un día de mi vida sí es difícil, porque nosotros ya de grandes un día más es un día para atrás, los niños, en cambio, es un día para delante. Y son los que más después van a ver lo difícil que viene todavía la vida. Más difícil todavía de lo que me tocó a mí. Hasta ahora, en la mañana, yo de campesino, me despierto a tomar un café y luego me pongo a ver qué se hace en el campo. Así es mi día. Luego, vengo a comer aquí y ya me salgo por allá a ver qué sale. 
A veces mis hijos vienen de vez en cuando. Pero como ahora en los Estados Unidos no está igual la cosa que antes, ya cambió todo. Y como mis hijos tienen su familia allá, nacidos allá. A penas les da para mantener a sus niños y estar tranquilos, de vez en cuando se acuerdan y mandan un poquito de dinero. Por eso ahora a mí esos mil pesos [Pensión para Adultos Mayores] sí me ayuda para las aguas, algo es. Pero eso sí, yo así de irme de aquí no lo pienso, porque ir a vivir con los hijos no es igual, ellos tienen a su familia y uno tiene su casa, no se acostumbra uno. Mudarme a vivir con uno de mis hijos, por ejemplo, no lo pienso. Porque aquí viví de un principio y aquí debe uno de morir, donde se fue feliz, donde es su casa de uno.

Don Abelito a sus setenta años dice sentirse "macizo"; es decir con una salud y condición física que le permite trabajar "galán”. Sin embargo, don Abelito reconoce que llegar a una mayor edad tendría otras implicaciones, pues sabe que sus situación económica y el hecho de no contar con ningún ingreso estable, más allá de los apoyos gubernamentales, lo llevaría a tomar decisiones que no quiere tomar, como quizá tener que mudarse a casa de alguno de sus desperdigados hijos, y quedar a su cuidado. Por tanto, él considera que debe morir en el lugar donde ha vivido $\mathrm{y}$, en sus palabras, ha sido feliz. El sentido trascendental de haber vivido y educado a su familia en esa tierra a la que llegó, primero a trabajar como jornalero y en donde ha habitado desde hace cincuenta años, evidencia un sentimiento de pertenencia a las actividades del campo y a la vida en el mundo rural. Lo cual, aunado a otras causas, ha hecho que no evacué en casos de emergencia su hogar, poniéndolo en evidente peligro, pues, como se mencionó, su casa está en riesgo de deslave. Don Abelito pertenece a una generación de campesinos mexicanos que ha vivido en constante disputa con estructuras que van más 
allá de sus fuerzas. Sin embargo, tenazmente son agentes de micro resistencias que van desde el discurso a la organización armada.

\section{Conclusiones}

Considero que el proceso de fundación de las localidades del Soconusco influye en las condiciones actuales de la región. Ya que este proceso nunca se consolidó, y aunque las tierras se entregaron y se cosecharon por años, se configuraron desde el inicio como unidades endebles. Esto, en parte, porque más allá de los primeros años de la Reforma Agraria, nunca hubo una intención Estatal real de culminar con el proceso de operatividad del proyecto ejidal.

Aunado a esto, desde el fondo mismo de la organización ejidal (agrupada en torno a una figura del grupo familiar, que regulaba el orden y la administración) las pequeñas unidades de producción de café se configuraron como mecanismos inestables, poco planeados y mal administrados. Lo que generó una dinámica compleja atravesada por diversas configuraciones de poder intrafamiliar. Sumado al hecho de que, en un inicio, aun dependían de las haciendas para procesar y comercializar el café, ya que no contaban con la maquinaría necesaria ni con los vínculos comerciales que les permitieran obtener ingresos significativos. Es decir, en términos reales, la vida en la sierra del Soconusco siempre fue precaria y dificultosa. Lo cual, paulatinamente convirtió estos ejidos en unidades productivas endebles, incapaces de afrontar con efectividad los cambios globales de la economía y del medio ambiente. Esto ha generado un desgaste acumulativo, que hace que los productores se encuentren ahora constantemente amenazados por la variación de los precios y las lluvias.

Revista Cadernos de Estudos Sociais e Políticos, v. 5, n. 9, jan-junho 2016 
Además, los propietarios se encuentran hoy, cada vez más, con menos fuerzas físicas y emocionales. Limitando de forma más acentuada, su capacidad de agencia, ante el peso de la pobreza estructural histórica, que soportan. 


\section{REFERENCIAS}

ALCALÁ MOYA, Graciela. Con el agua hasta los aparejos, pescadores y pesquerías en el Soconusco, Chiapas. México: Centro de Investigación y Estudios Superiores en Antropología Social, Universidad de Ciencias y Artes del Estado de Chiapas, 1999.

ÁNGELES, Hugo. "Más que una bebida. El cultivo del café en Chiapas trabajadores guatemaltecos". Café y frontera, 2012, pp. 20-21. Disponível em:

$<$ http://www.ecosur.mx/ecofronteras/ecofrontera/ecofront 12/tabajedores $\% 20$ guatemeltecos.pdf $>$.

ARIZA, Marina; DE OLIVEIRA, Orlandina. "Familias en transición y marcos conceptuales en redefinición". Papeles de Población, vol. 7, n 28, 2001, pp. 2-32.

. Imágenes de la familia en el cambio de siglo. Instituto de Investigaciones Sociales y Universidad Nacional Autónoma de México, 2004.

BENJAMIN, Thomas. “¡Primero viva Chiapas! La revolución mexicana y las rebeliones sociales", in J. Viqueira e M. Ruz (eds.), Chiapas: los rumbos de otra historia. México: IIF-UNAM/CIESAS, 1995.

DE LA FUENTE, Julio. Monopolio de aguardiente y alcoholismo en los Altos de Chiapas: un estudio incómodo de Julio de la Fuente, 1954-1955. México: Comisión Nacional para el desarrollo de los Pueblos Indígenas, 2009.

GRAMMONT, Hubert C. de. "La nueva ruralidad en América Latina". Revista Mexicana de Sociología, ano 66, número especial. México: Universidad Nacional Autonóma de México, 2004.

GROLLORÁ, Daniela. "Los trabajadores cafetaleros y el Partido Socialista Chiapaneco 1920-1927”, in J. Viqueira e M. Ruz (eds.), Chiapas los rumbos de otra historia. México: Centro de Investigación y Estudios Superiores en Antropología Social, 1995.

INSTITUTO NACIONAL DE ECONOMÍA SOCIAL. Beneficios del café, 2014. Disponível em:

Revista Cadernos de Estudos Sociais e Políticos, v. 5, n. 9, jan-junho 2016 
$<$ http://www.inaes.gob.mx/doctos/pdf/guia_empresarial/beneficios_del_cafe. pdf $>$.

KAY, Cristóbal. "Estudios rurales en América Latina en el periodo de globalización neoliberal: ¿Una nueva ruralidad?”, Revista Mexicana de Sociología, vol. 71, nº 4, 2009, pp. 607-645.

LONG, Norman. Sociología del desarrollo: una perspectiva centrada en el actor. México: Centro de Investigaciones y Estudios Superiores en Antropología Social - El Colegio de San Luis, 2007.

MAHNKEN, Winifred. Mi vida en los cafetales, Tapachula (1882-1992). Tuxtla Gutiérrez: Gobierno del Estado de Chiapas, 1993.

MOLINA PÉREZ, Valente. Los rieles de Chiapas: construcción del Ferrocarril Panamericano. Tuxtla Gutiérrez: Gobierno del Estado de Chiapas, 2006.

REYES HERNÁNDEZ, Diana Isabel. Por la promoción de una cultura de protección civil aplicada al municipio de Tapachula de Córdova y Ordóñez, Chiapas. Caso Huracán Stan. Tesis de Licenciatura Inédita, Universidad de las Américas Puebla, 2006.

SECRETARÍA DE AGRICULTURA, GANADERÍA, DESARROLLO RURAL, PESCA Y ALIMENTACIÓN. Procampo, en qué consiste y cómo surguipo, 2014. Disponível em:

$<$ http://w4.siap.sagarpa.gob.mx/sispro/comunes/PortalesFijos/ligasapoyo/pro campo.htm>.

ULLOA GARCÍA, Armando. Huixtla, lugar de Espinas-Ciudad de Espinas. Tuxtla Gutiérrez: Universidad de Ciencias y Artes de Chiapas, 2005.

VÁZQUEZ PALACIOS, Felipe (comp). Contando nuestros dias, un estudio antropológico sobre la vejez. México: Centro de Investigación y Estudios Superiores en Antropología Social, 2003.

. "Envejeciendo en las tradicionales y nuevas realidades".

Intersticios Sociales, ${ }^{\circ}$ 5, 2013, pp. 3-29.

VERSCHUEREN, Jef. Para entender la pragmática. Madrid: Gredos, 2002. 
VIQUEIRA, Juan Pedro; RUZ, Mario Humberto (Eds.). Chiapas los rumbos de otra historia. México: Centro de Investigación y Estudios Superiores en Antropología Social, 2002.

VON MENTZ, Brigida et al. Los empresarios alemanes, el Tercer Reich y la oposición de derecha a Cárdenas. México: Centro de Investigación y Estudios Superiores en Antropología Social, 1988.

ZEMON DAVIS, Natalie. "Las formas de la historia social”. Fundación Instituto de la Historia Social, nº10, 1991, pp. 117-182.

WEBER, Max. La ética protestante y el espíritu del capitalismo. México: Premia Editora-La Red de Jonás, 1991.

Recebido em: 16/06/2015

Aprovado em: 05/02/2016 